\title{
Stakeholder engagement in radiological protection: Developing theory, practice and guidelines
}

\author{
C. Turcanu ${ }^{1, *}$, M. Van Oudheusden ${ }^{1}$, B. Abelshausen ${ }^{1}$, C. Schieber ${ }^{2}$, T. Schneider ${ }^{2}$, N. Zeleznik ${ }^{3}$, \\ R. Geysmans ${ }^{1}$, T. Duranova ${ }^{4}$, T. Perko ${ }^{1}$ and C. Pölzl-Viol ${ }^{5}$ \\ ${ }^{1}$ SCK-CEN - Belgian Nuclear Research Centre, Boeretang 200, Mol, Belgium. \\ ${ }^{2}$ CEPN-Nuclear Protection Evaluation Centre, 28 rue de la Redoute, 92260 Fontenay-aux-Roses, France. \\ ${ }^{3}$ EIMV - Milan Vidmar Electric Power Research Institute, Hajdrihova 2, Ljubljana, Slovenia. \\ ${ }^{4}$ VUJE-Okruzna 5, 91864 Trnava, Slovak Republic. \\ ${ }^{5}$ BfS-Federal Office for Radiation Protection, Willy-Brandt-Straße 5, Salzgitter, Germany.
}

\begin{abstract}
The European project ENGAGE investigated formal or informal demands and expectations for stakeholder engagement in radiological protection, and their translation into practices at national and local levels. Three contexts were examined in detail: nuclear emergency preparedness, response and recovery; exposure to indoor radon; and medical exposures to ionising radiation. Research showed that prescriptions and practices for stakeholder engagement would benefit from acknowledging the normative and substantive rationales for engagement. It suggests broadening participation both in terms of stakeholders - particularly from the perspective of integration of radiological protection into broader frameworks - and the forms of participation - for instance by recognising the importance of informal and citizen-led engagement. In addition, more systematic approaches for stakeholder engagement should be included in the elaboration and evaluation of national policies. Finally, results substantiate the need for developing radiological protection culture in a participatory, multi-disciplinary way. Recommendations for more robust stakeholder engagement in radiological protection are formulated based on the findings.
\end{abstract}

Keywords: stakeholder engagement / ionising radiation / radiological protection culture / ENGAGE

\section{Introduction}

Engagement of stakeholders, including wider publics, in radiological protection has become a key topic for researchers, practitioners, policy-makers and civil society organisations. This is reflected in a wide variety of generic guidelines and recommendations, strategic research agendas of radiological protection research platforms, and research projects and initiatives at international and national levels (e.g. Nisbet et al., 2005; HERCA, 2008; IRPA, 2008; CIP, 2009; IAEA, 2014; NTW, 2015; OECD, 2015; Baudé et al., 2016; Raskob et al., 2016; SAFECAST, 2016, p. 12; Perko et al., 2019).

However, there are challenges in the practical implementation of policies and legal requirements for stakeholder engagement, for instance ensuring resources for sustainable engagement, attracting long term involvement, or addressing divergences on who to involve, at which stage, and what the outcome of engagement should be (NTW, 2015; Liland and

*Corresponding author: catrinel. turcanu@sckcen. be
Raskob, 2016). Moreover, in both research and practice, considerably more attention has been given to invited participation initiated by governmental actors or research institutions, than to other forms of bottom-up or citizen-led engagement (Wynne, 2007). Finally, while the establishment of radiological protection culture has received increasing attention in the past decade (e.g. IRPA, 2014), its characterisation in different exposure contexts by/for different stakeholders, as well as its interaction with stakeholder engagement have not been addressed in a systematic way (Perko et al., 2019).

To cover these gaps, the European project ENGAGE ("ENhancinG stAkeholder participation in the GovernancE of radiological risks for improved radiation protection and informed decision-making") investigated the formal or informal demands and expectations for stakeholder engagement, and how these are translated into practices at national and local levels. It focused on three contexts of exposure to ionising radiation: nuclear emergency preparedness, response and recovery; indoor radon; and medical exposures to ionising radiation. The objectives were: 
- to analyse the formal discourses prescribing or recommending engagement, as formulated in international and national legislations and guidelines, and mobilised by different actors;

- to highlight the forms of participation that can be observed in practice, and potential gaps between prescriptions and practices;

- to investigate processes for enhancing radiological protection culture and their role in facilitating stakeholder engagement and informed decision making;

- to develop novel approaches to analysing stakeholder interaction and engagement;

- to design a knowledge base and formulate recommendations for a more robust stakeholder engagement in radiological protection.

Sections 2 and 3 provide details on the concepts and methodology employed in the project, while the subsequent sections summarise the main results and conclusions from this study.

\section{Sensitising concepts for analysis}

Stakeholder engagement is conceptually framed within, and stems from, theories and practices on participation. For the purpose of analysis, a number of terms have been used within ENGAGE as "sensitizing concepts" to indicate possible lines of inquiry that can be adapted to the case at hand and the developments that ensue during fieldwork (van den Hoonard, 1997).

First, for the concept of stakeholder, there is no consensus among researchers and practitioners, in general, and among radiological protection communities, in particular, on "who" has a stake, and "what" is at stake in radiological protection. This lack of consensus is also an asset as it leads to in-depth discussions on why, who and how stakeholders should, can or will be involved in decision-making processes (Miles, 2012). ENGAGE investigated how the concept of stakeholders is defined in regulations and guidelines relevant to radiological protection, and how this concept is mobilised by different actors. The project adopted a broad understanding of stakeholders as: actors (individuals or groups, institutional and non-institutional) with a tangible or intangible (yet to be shaped or discerned) interest in the radiation exposure situation and the related radiological protection issues. These actors may be affecting decisions, be affected by the formulation and resolution of a problem or challenge, or represent an affected party (humans or the environment). In this perspective, stakeholders are constructed by their interaction with actors, issues, contexts.

Second, ENGAGE recognised that participation is a reality that occurs in different forms. Various models of participation have been proposed by scholar and practitioners (Abelshausen et al., 2015). Throughout the last decades, these models have evolved from hierarchical models of participation, to models wherein each type of participation has its own merit. ENGAGE recognised the plurality of engagement concepts and the continuum between formal and informal participation, institutional and citizen-led participation, lower and higher levels of involvement and influence on agenda-setting and decision-making on environmental or science and technology issues. Therefore, it did not adopt a predefined definition of engagement ${ }^{1}$. Instead, it traced the prescriptions for and practices of engagement, and the meanings these entail. Within analyses, an adapted version of the horizontal model of Health Canada (2000) was considered as a benchmark for stakeholder participation, wherein each type has its own merit depending on the context. This includes: providing information/education, gathering information from stakeholders, consultation/discussion with individual stakeholders, multi-stakeholder collaboration/dialogue, partnering, and citizens' actions. The project took into account that invited participation by institutional actors is only one part of a more complex relational system, which includes also other forms of engagement, such as citizen-led initiatives.

Third, different rationales for participation were studied, focusing on substantive, instrumental and normative motivations (Stirling, 2008). A substantive motivation highlights the improvement of decisions, policies and assessments by including a plurality of viewpoints. An instrumental motivation characterizes participation as a means to an end, and is reflected in the intent to support preconceived, often short-term policy commitments (e.g. educating citizens about science). And a normative or democratic motivation is grounded on the values and ethics underlying participation (e.g. the moral right to participate of potentially affected people). Within ENGAGE, dominant rationales for participation were determined, as defined or mobilised by different actors.

Finally, ENGAGE studied radiological protection culture (RP culture), particularly its role and potential benefit to facilitate stakeholder engagement. RP culture is here understood as a concept of composite nature, characterized by a set of perceptions, values, attitudes, beliefs and expectations related to radiation risk; an assembly of knowledge, knowhow, skills, experience, and practices related to radiological protection; and a dynamic development process based on multi-stakeholder interactions (IRPA, 2014). From a general point of view, the aims of RP culture are manifold. First, it favours an understanding of radiological protection norms and standards. Second, it enables individuals to reflect on their own protection and/or that of others, consciously consider radiological protection aspects in their lives, and contribute to decision-making processes related to the management of radiological exposure situations. Thirdly, it enables professionals in radiological protection and other stakeholders to participate in a dialogue, share a common language, with a view to enhance decision-making processes associated with the implementation of the radiological protection system, and better address the concerns of all stakeholders.

\section{Methodology}

\subsection{Rationales and frames for engagement}

A first objective of ENGAGE was to analyse the rationales and frameworks for stakeholder engagement in radiological

\footnotetext{
${ }^{1}$ In some models, engagement and participation are treated as distinct concepts, referring to particular forms of interaction between stakeholders and/or influence on decisions. In this paper, for the reasons mentioned above, engagement and participation are used interchangeably, as overarching framework.
} 
protection. The focus was participation at macro-level, as highlighted in European and international discourse, and transposed at national level in participating countries. A template for analysis was developed, centred on the following key research questions:

- What local, regional, national or international - formal or informal - policies or actors justify or prescribe stakeholder engagement in radiological protection?

- Which actors are summoned/expected to engage, by whom, when, and how? How do policy-makers, regulators, civil society organisations and international organisations define "stakeholders" and how do they understand stakeholder engagement? What are their expectations from such processes?

- Can aspirations for or trends (over time) towards more or less engagement of particular social groups be identified? Are there any tensions, ambiguities, contradictions, or divergences present in, or indicated by, these prescriptions?

- What potential implications do these conceptions entail for radiological protection institutes, communities, research platforms, and researchers?

Data were collected through document analysis (legal, binding requirements as well as guidelines from different international organisations) and interviews with representatives from international organisations for each of the three fields: emergency preparedness, response and recovery; exposures to indoor radon; and medical exposures to ionising radiation (Zeleznik et al., 2019a). Roundtables on stakeholder engagement provided for in-depth discussions and collection of additional data.

\subsection{Developing case studies on participation practices}

A second objective of ENGAGE was to highlight through case studies the forms of participation that can be observed in practice, with attention to the issues at stake; the ways outcomes and processes of participation are crafted; the main challenges and opportunities; and how these practices relate to the frames set by the legislative documents and guidelines analysed. Case studies were selected to cover a broad range of participation practices in the three exposure contexts in different European countries. Attention was directed both at formal and informal participation, which are distinguished by the fact that formal engagement is organized along the lines of policy prescriptions, whereas informal engagement exists independently of such requirements. An illustration of the former can be found in legally required consultations with stakeholders in establishing emergency plans, whereas grassroots citizen science initiatives can offer an example of informal engagement (see Geysmans et al., 2020).

In total, 15 national case studies of stakeholder engagement in practice have been developed in three exposure contextsmedical exposures (Cantone et al., 2019), indoor radon (Turcanu et al., 2019a) and emergency preparedness, response and recovery (Zeleznik et al., 2019c) to address the aforementioned questions.

\subsection{Developing case studies on radiological protection culture}

A third objective of ENGAGE was to study the role and potential benefit of radiological protection culture to facilitate stakeholder engagement and informed decision-making. The key research questions were: i) how is radiological protection culture characterised and evaluated?; ii) how does building and enhancing RP culture support stakeholder engagement and informed decision-making?; and iii) what are the processes to build and transmit RP culture in different exposure contexts? Belarus, France, Italy, Greece, Slovak Republic, and Switzerland were identified to cover the exposure contexts studied within ENGAGE: medical field, indoor radon management, and emergency preparedness, response and recovery. A common analysis grid was elaborated, structured around the following topics:

- characterisation of the case study including type of actions/ processes analysed from the point of view of RP culture dissemination, and description of the main target stakeholders;

- aim of RP culture for the various stakeholders including elements contributing to this culture;

- description of tools, methods and processes to build, enhance and transmit RP culture including investigation of processes' efficiency and sustainability;

- evaluation of the level of RP culture.

Ten case studies on radiological protection culture have been analysed following this grid, based on the practical experience of project participants in the actions or processes described. Interviews with some key actors were used to complete the analysis. A dedicated stakeholder workshop has been organised to discuss the findings from case studies (Schieber and Schneider, 2019). This provided elements to further elaborate the lessons learned and formulate recommendations for building RP culture in the various fields, and to identify further research needs (Barazza et al., 2019).

\subsection{Developing and adapting novel research methods}

A fourth objective of ENGAGE was to develop novel approaches to analysing stakeholder interaction and engagement. Besides the dedicated research methodologies for the macro-level analysis and the case studies described in the previous subsections, novel methods were developed or adapted for specific studies concerning stakeholder participation in radiological protection.

\subsubsection{Mapping stakeholder engagement: identifying dominant and deviant cases}

Commencing from the hypothesis that some stakeholders and forms of participation are dominant in terms of prevalence and recognition, a methodological strategy was developed to uncover those forms of participation which are rare or unique in a particular area. The method was tested in the field of nuclear emergency management in Belgium. A two-step sampling approach was developed. In a first step, a Google 
search was performed with search words (translated in Dutch and French) including combinations of terms referring to "nuclear emergency", "emergency plan" or "radioactivity", with terms such as "participation", "meeting", "action", "protest", "stakeholder", "citizen" or "population". The aim was to generate a systematic mapping of existing activities (Pallett et al., 2017) providing a broad overview of stakeholder engagement initiatives in relation to nuclear emergency management in Belgium. Parameters of the search engine were set to identify material published in Belgium over a 10 years period (2009-2019). A screening was applied to eliminate duplicates and entries unrelated to any form of engagement in emergency management ( 150 web pages retained from more than 1000 initial hits). In a second step, we identified (in an inductive way) those cases which were remarkable, unique or rare. This process of "deviant sampling" (cf. Suri, 2011) encompassed a more in-depth analysis of the different cases in the database. This revealed forms of engagement dominant in terms of their prevalence, as well as forms which were deviant, for instance in terms of stakeholders involved, objects and media concerned in the engagement activity, initiators of the activity, and/or purpose of the activity.

This method has several merits. First, it provides a broad overview of existing stakeholder engagement initiatives in a defined context. Second, it can potentially identify stakeholders and forms of engagement which might remain undetected when pertaining only to more dominant understandings. Third, it provides opportunities for reflection on potential futures or alternatives of participation, and societal power dimensions shaping current understandings of stakeholder engagement. When conducted at different time intervals, or with different geographical emphases, this two-step sampling approach also holds the potential to trace changes in stakeholder engagement, highlighting how what is dominant and deviant evolves over time and/or space, in accordance with power dynamics. A potential pitfall of the current implementation is that the search engine acts as a gatekeeper and potentially hinders identification of cases which are not available through this access point. The forms of participation identified through this method have thus been usefully complemented with results from a search in academic literature (Google scholar) and information obtained from emergency management researchers and practitioners.

\subsubsection{Analysis of websites as potential facilitators of engagement}

To analyse to what extent radon websites are or can be used to facilitate engagement in radon risk management, a combination of automated and manual evaluation methods was developed for website analysis (Perko and Turcanu, 2020). Following Karkin and Janssen (2014), Coleman et al. (2008), Domarkas et al. (2012) and Siar (2005), a number of website evaluation metrics were adapted for the context of radon mitigation. One hundred and seventy-three websites of national, regional and local authorities responsible for radon issues or located in radon prone areas have been evaluated in 11 European countries. The evaluation criteria were defined and assessed as follows:
- availability of radon information: automated and manual check with "radon" as search word, and analysis of all pages and sub-pages related to health, environment, policies and news;

- accessibility from mobile devices: presence or absence of a mobile friendly version;

- personalized content: possibility to obtain radon information corresponding to a specific address or location; interactive radon map; map with radon concentrations;

- broken links on the internet pages: automatic evaluation using W3C standards ${ }^{2}$, recursion depth level 3;

- interaction with stakeholders: feedback forms or satisfaction questionnaires; Q\&A tools as an open category; possibility to propose ideas, e.g. related to radon actions; broadcasting related to the radon program or events/ meetings (e.g. TV broadcasts, documentaries, public meetings, Webinars); direct personal communication ( $e$. g. e-mail address) with the responsible for radon; usercentred design (e.g. Facebook, Twitter, YouTube);

- dialogue between stakeholders: presence or absence of chat areas or message boards;

- responsiveness of the authorities: response to an e-mail sent to each institution dealing with radon issues presented on the website; evaluated quantitatively (days before response) and qualitatively (empathy, concern). Another indicator: use of social media plugs;

- content and design for different stakeholder groups: userfriendliness and usability, e.g. how quickly (number of clicks) can information be found, such as cost of radon measurement kit, or where to get it from; the presence of stories; subpages dedicated to specific stakeholder groups;

- transparency and openness: online availability of: list of analysis laboratories; national radon action radon plan and financial documents related to it; European BSS Directive; other national legislation; radon mapping plan; locations for radon mitigation activities.

This method allowed the identification of good practices for radon websites and can be adapted to other fields, for instance medical exposures or emergency preparedness, response and recovery.

\subsubsection{Participatory mapping}

Picture a giant tableau and a small table with markers, situated in a large conference hall where people chat over coffee and biscuits. The tableau is blank, waiting to be written on.

This was the setting of a participatory mapping exercise at the 2018 Radiation Protection Research Week in Rovinj (Croatia), where social scientists invited conference attendees to write and draw their thoughts about stakeholder engagement in radiological protection. In the course of three days, a full map emerged assembling stakeholder names, relationships, practices, and visions of stakeholder engagement for the future. This exercise was a first step towards gaining a better sense of the expectations, views, and experiences of the radiological protection community - particularly researchers with respect to "engagement".

\footnotetext{
${ }^{2}$ http://www.w3.org/WAI/standards-guidelines/w3c-process/\#stan dards.
} 


\section{Results}

Using a set of proven and novel methodologies, an analysis was conducted of rationales and frameworks for stakeholder engagement and participation practices in three contexts: emergency preparedness, indoor radon and medical exposures to ionising radiation. Research highlighted both specificities (Geysmans et al., 2020; Kenens, 2020; Schieber et al., 2020; Turcanu et al., 2020), as well as similarities regarding stakeholder engagement across these different exposure contexts. In all three fields, the relevance of stakeholder participation, including wider publics, is increasingly recognised by institutional and non-institutional actors. However, in many (inter)national regulatory frameworks, stakeholder engagement - if prescribed - is little elaborated upon. This causes uncertainty and potential mismatch of expectations regarding issues such as: when to initiate stakeholder engagement, who to involve at which stage and what to expect from it, as well as which (legal or not) basis can foster the participatory process. Interactions with radiation protection researchers and practitioners by means of participatory mapping confirmed the aforementioned findings: most participants recognised the importance of stakeholder engagement in radiological protection and acknowledged that no stakeholder can be wilfully excluded. However, there was a shared unease or uncertainty about how to organize engagement (when to initiate it, whom to involve at which stage, what to expect from it). Results also suggest the need for more systematic approaches to stakeholder engagement in national policies. Several recommendations of ENGAGE originate from and relate, at least partially, to this issue.

Recognizing that any form of engagement entails assumptions about what is at stake, who should or could participate, and what the outcome of the engagement process should be, it is apparent that engagement is no "neutral space" (Turnhout et al., 2010), but instead connects to processes of power and dominance prevailing in broader societies (Chilvers and Burgess, 2008). Research showed that in all three fields, a distinction is often made between formal engagement of professional/institutional stakeholders and that of broader publics. For example, in many prescriptions on stakeholder engagement in emergency preparedness and recovery, stakeholders are defined either as emergency managers, or (possibly) affected publics, with different forms of engagement proposed for these different groups. In most cases, it is professionals and institutional stakeholders who are involved in collaboration and joint decision-making. Although a gradual institutional shift can be noticed from the public knowledge deficit frame to dialogue (Smallman, 2016), engagement of wider publics is mostly seen as a means to raise public awareness and communicate, or to trigger predefined radiological protection actions. While this can be a valuable motivation in itself, it misses a wider view on what stakeholder engagement can deliver. Several recommendations direct therefore attention towards the normative and substantive rationales for engagement.

With few exceptions of national policies in some European countries, the analysis of legal requirements (Zeleznik et al., 2019b) suggests an emphasis on formal, top-down participa- tion, which varies from information to consultation, although the focus is on provision of information from the responsible actors to other stakeholders. The main motivation for participation points often towards an instrumental use of stakeholder engagement as a way to secure particular end points (e.g. gaining acceptance for specific radiological protection actions). In few instances, normative (e.g. transparency in emergency preparedness and response, or patients' right for information in the medical field), and substantive rationales (e.g. improved decision-making) can also be discerned. The recently adopted revision of the European Basic Safety Standards directive opens opportunities for enhanced participation, particularly for the areas of nuclear emergency preparedness and recovery, and radon risk management. Other actors or policies, for instance recommendations and guidelines of international organisations or associations, reflect a broader view on stakeholder engagement in comparison with legal frameworks, not only in terms of interpretation of concepts such as "stakeholder" and "involvement" or "engagement", but also with regards to the motivations or aspirations underlying the calls for participation. These support enhanced interactions with different groups of stakeholders in activities relating to ionising radiation and suggest a very broad representation of stakeholders.

In the field of emergency and recovery management, ENGAGE demonstrated the existence and importance of informal stakeholder engagement. This incites reflection on the existence and possible contribution of informal engagement in other exposure contexts (e.g. citizen science in radon management), which would benefit from further exploration. Besides dominant forms of stakeholder engagement, which mostly encompass formal, top-down initiatives (e.g. public information evenings organized by nuclear authorities, parliamentary questions, emergency exercises and general awareness campaigns), there are also deviant cases. Examples of the latter include a local residents' initiative to restore and commemorate a nuclear artwork in their municipality, an awareness campaign on actions to be taken during nuclear emergencies initiated by local partnerships operating in the field of radioactive waste management, an entrepreneur marketing the conversion of basements to emergency shelters, protest actions of inhabitants of neighbouring countries or citizens' monitoring networks.

Another common theme across the three fields is the call for integrating radiological protection in broader frameworks, e.g. integrating radon risk mitigation in a broader environmental and public health protection approach focused on indoor air quality; integrating radiological protection into the general, patient-centred healthcare in the medical sector; or integrating nuclear emergency and recovery management in multi-hazard approaches. This highlights the importance of identifying and explicitly considering new stakeholders stemming from this integration (both vertically, at different governance levels, as well as horizontally, corresponding to different fields), and recognising their potential roles and responsibilities in radiological risk governance.

Radiological protection culture, including its aims, target stakeholders and potential role were characterised in different exposure contexts (Barazza et al., 2019). Research highlighted 
Emergency Preparedness, Response and Recovery (EPR\&R)

1 Broaden the motivation for stakeholder engagement in EPR\&R, in both prescriptions and practice.

2 Broaden the scope of participation in EPR\&R

3 Recognise the role of informal stakeholder engagement in EPR\&R.

4 Integrate stakeholder engagement in EPR\&R plans and policies.

5 Establish strategies for continuous, 2-way communication about emergency and recovery planning, tailored to specific

stakeholders from both local and wider areas.

6 Elaborate a strategy to foster development of radiological

protection culture in the preparedness phase.
Indoor radon

1 Broaden the motivation for stakeholder engagement in indoor radon management, in both prescriptions and practice.

2 Include in radon action plans a structured approach to stakeholder engagement in the design, implementation \& evaluation of actions.

3 Integrate radon risk management into a comprehensive environmental and public health protection approach, with engagement. of all stakeholders connected to these issues

4 Support the development of context specific, local / regional approaches for stakeholder engagement in radon management.

5 Develop multidisciplinary, multi-level and multi-stakeholder, participatory approaches to build, enhance and transmit radon radiological protection culture.

Medical exposures

1 Engage initiatives to develop and promote radiological protection culture for the health professionals who are not directly involved in medical procedure using ionizing radiations but may be occupationally exposed and/or interact with patients.

2 Integrate or reinforce radiological protection culture as part of medical practices for the medical professionals who are directly involved in medical procedures using ionizing radiations

3 Create spaces and tools for patient engagement in the medical use of ionising radiations.

Fig. 1. ENGAGE recommendations for stakeholder engagement in radiological protection.

some particularities. In emergency and recovery management, it incited reflection on the role of radiological protection culture in the preparedness phase and argued that its aim is to allow stakeholders to reflect on what is at stake in case of a nuclear accident, not only from a radiological point of view, but also concerning the consequences in the daily life of affected populations. In relation to radon, key points were having radon considered as a public health issue and integrating it into indoor air quality management and the need to build and enhance radiological protection culture for the different stakeholders relevant to these areas. In the medical field, our analysis showed a need to reinforce initiatives to develop and promote radiological protection culture not only for medical professionals directly involved in the implementation of medical procedures using ionizing radiations, but also those who are not directly involved, but may be occupationally exposed and/or interact with patients and/or prescribe medical exams. This includes nurses, general practitioners or other referrers. Finally, ENGAGE emphasized that these three fields are characterized by the need for developing the radiological protection culture in a participatory way for the various stakeholders involved in the management of the exposure situations. Besides being developed through the participation of stakeholders, this also takes stakeholder engagement as a central condition of the implementation of the radiological protection system.

\section{Knowledge base}

A design concept was proposed for a knowledge base that can contribute to learning from past experience, highlighting challenges and opportunities for stakeholder engagement, and thus help shape and improve future participation processes in the three fields. The concept aims at documenting a wide range of participatory practices, taking into account the specific context of three radiation exposure contexts studied. It builds on past actions developed by the NERIS platform (French et al., 2014), and the OECD (OECD, 2016) with adaptations made to highlight key elements addressed by the ENGAGE project. The database structure includes seven sections: provider of information, general description (e.g. objectives, context, initiator, organiser, funding body), participants (opportunities, motivations), process (participation forms and methods, evaluation, flexibility, ethical consideration), ex-post assessment (e.g. challenges, outcome, feedback from participants), practical information, and additional information (e.g. links to reports). The knowledge base concept was illustrated with four case studies conducted within ENGAGE (Duranova et al., 2019). The concept proposed promotes reflection on the different forms of, and motivations for, engagement and should be of interest for the radiological protection stakeholders. Further steps of knowledge base development could comprise the operational realisation and implementation.

\section{Conclusions}

ENGAGE addressed stakeholder engagement in three contexts of exposure to ionising radiation, which are the highest - actual or potential - contributors to ionising radiation doses to the public: nuclear emergency preparedness, response and recovery, exposure to indoor radon; and medical exposures to ionising radiation. In these three fields, it directed the focus towards prescriptions and practices for stakeholder engagement. It investigated formal or informal demands and expectations for stakeholder engagement, and how these are translated into practices at national and local levels. It also highlighted the role potential benefit of developing radiological protection culture.

A set of recommendations (Fig. 1) were developed for more robust stakeholder engagement in radiological protection (more details in Turcanu et al., 2019b and www.engage- 
concert.eu), based on findings from the research and participatory activities conducted throughout the project, as well as input from a wide range of stakeholders, notably during the final ENGAGE project workshop (Bratislava, 11-13 September 2019).

The findings and recommendations from the ENGAGE project are intended for radiological protection researchers and practitioners, policy makers, and civil society stakeholders and publics, who should work together to develop more robust radiological protection policies and governance. Further research should focus on implementation and validation of ENGAGE recommendations in practice in different national and local contexts.

Acknowledgements. The work described in this paper was conducted within the ENGAGE project, which was part of the H2020 CONCERT project. This project received funding from the EURATOM research and training programme 2014-2018 under grant agreement No 662287.

Disclaimer (Art. 29.5 GA). This publication reflects only the author's view. Responsibility for the information and views expressed therein lies entirely with the authors. The European Commission is not responsible for any use that may be made of the information it contains.

\section{References}

Abelshausen B, Vanwing T, Le Xuan T. 2015. Participation throughout the decades: How zeitgeist influences both theory and practice - A case study. Procedia Soc. Behav. Sci. 191: 1713-1717.

Barazza F, Cardis E, Cantone M-C, Charron S, Doremus P, Duranova T, Economides S, Gschwind R, Lafage S, Liutsko L, Murith C, Schieber C, Schneider T. 2019. Final report on case studies, including recommendations and guidelines on building and enhancing radiation protection culture. CONCERT Deliverable D9.87.

Baudé S, Heriard-Dubreuil G, Eikelmann IM, Boilley D, Schneider T. 2016. Local populations facing long-term consequences of nuclear accidents: Lessons learnt from Chernobyl and Fukushima. Radioprotection 51(HS2): 155-158.

Cantone M-C, Pölzl-Viol C, Abelshausen B, Economides S, Liutsko L, Savu D, Schieber C, Zeleznik N, Zorko B. 2019. Report on venues, challenges, opportunities and recommendations for stakeholder engagement in the medical field. CONCERT Deliverable D9.89.

Chilvers J, Burgess J. 2008. Power relations: The politics of risk and procedure in nuclear waste governance. Environ. Plan. A 40(8): 1881-1900.

CIP. 2009. Cowam in practice. European-level guidelines for the inclusive governance of radioactive waste management.

Coleman R, Lieber P, Mendelson AL, Kurpius DD. 2008. Public life and the internet: If you build a better website, will citizens become engaged? New Media Soc. 10(2): 179-201.

Domarkas V, Laukaityte A, Mačiukas V. 2012. Assessment of development level of municipal websites of the Republic of Lithuania. Public Policy Adm. 11(1): 23-36.

Duranova T, Pölzl-Viol C, Turcanu C, Geysmans R, Abelshausen B, Schieber C, Croüail P, Zeleznik N, Economides S, Barazza F, Fallon C. 2019. Knowledge base for designing and documenting stakeholder engagement process. CONCERT Deliverable D 9.92 .

French S, Schneider T, Croteau C, Oughton D, Tomkiv Y, Papamichail N. 2014. Designing and reporting stakeholder workshops and public participation: Proposal for a building a knowledge base. NERIS Platform report, Version 6.0.

Geysmans R, Zeleznik N, Abelshausen B, Duranova T, Schieber C, Schneider T, Crouail P, Turcanu C, Liutsko L, Cantone MC. 2020. Broadening and strengthening stakeholder engagement in emergency preparedness, response and recovery. Radioprotection 55(HS2). https://doi.org/10.1051/radiopro/2020037.

Health Canada. 2000. Health Canada policy toolkit for public involvement in decision making.

HERCA. 2008. Stakeholder Involvement in medical practices. Report of the HERCA Working Group 5. France. Available from https:// www.herca.org/documents/Stakeholder\%20Involvement $\% 20 \mathrm{in} \%$ 20Medical\%20Practices\%2020081212.pdf.

IAEA. 2014. Communication and stakeholder involvement in environmental remediation projects. Nuclear Energy Series No. NW-T-3.5. Vienna: International Atomic Energy Agency.

IRPA. 2008. IRPA Guiding principles for radiation protection professionals on stakeholder engagement. International Radiation Protection Association.

IRPA. 2014. Guiding principles for establishing a radiation protection culture. International Radiation Protection Association.

Karkin M, Janssen M. 2014. Evaluating websites from a public value perspective: A review of Turkish local government websites. Int. J. Inf. Manag. 34: 351-363.

Kenens J. 2020. Changing perspectives: Tracing the evolution of citizen radiation measuring organizations after Fukushima. Radioprotection 55(HS2). https://doi.org/10.1051/radiopro/ 2020041.

Liland A, Raskob W, Eds. 2016. Towards a self-sustaining European platform on nuclear and radiological emergency preparedness, response and recovery. Radioprotection 51(HS1). https://doi.org/ 10.1051/radiopro/2016002.

Miles S. 2012. Stakeholder: Essentially contested or just confused? J. Bus. Eth. 108(3): 285-298.

Nisbet AF, Mercer JA, Rantavaara A, Hanninen R, Vandecasteele C, Carlé B, Hardeman F, Ioannides KG, Papachristodoulou C, Tzialla C, Ollagnon H. 2005. Achievements, difficulties and future challenges for the FARMING network. J. Env. Rad. 83(3): 263-274.

NTW. 2015. Report of NTW Working Group on Emergency Preparedness and Response (EP\&R). Available from http:// www.nuclear-transparency-watch.eu/wp-content/uploads/2015/ 04/NTW-Report.pdf.

OECD. 2015. Stakeholder involvement in decision making: A short guide to issues, approaches and resources. Paris: NEA No. 7189.

OECD. 2016. Pilot database on stakeholder engagement practices. Available from www.oecd.org/gov/regulatory-policy/pilot-data base-on-stakeholder-engagement-practices.htm.

Pallett H, Chilvers J, Hargreaves T. 2017. Mapping energy participation: A systematic review of diverse practices of participation in UK energy transitions, 20102015. London: UKERC.

Perko T, Turcanu C. 2020. Is internet a missed opportunity? Evaluating radon websites from a stakeholder engagement perspective. J. Env. Rad. 212: 106123.

Perko T, Van Oudheusden M, Turcanu C, Pölzl-Viol C, Oughton D, Schieber C, Schneider T, Zölzer F, Mays C, Martell M, Baudé S, Choffel de Witte I, Prlic I, Cantone M-C, Salomaa S, Duranova T, Economides S, Molyneux-Hodgson S. 2019. Towards a strategic research agenda for social sciences and humanities in radiation protection. J. Rad. Prot. 39(3): 766.

Raskob W, Schneider T, Gering F, Charron S, Zheleznyak M, Andronopoulos S, Heriard-Dubreuil G, Camps J. 2016. Innovative 
integrative tools and platforms. Key results of the PREPARE European Project. Radioprotection 51(HS2): S59. https://doi.org/ 10.1051/radiopro/2016032.

SAFECAST. 2016. The SAFECAST Report. Vol 2, March 2016.

Schieber C, Schneider T. 2019. Stakeholder Workshop: Development of radiological protection culture to support the governance of radiological risk. CONCERT Deliverable D 9.84. Available from https://concert-h2020.eu/en/Publication.

Schieber C, Pölzl-Viol C, Cantone M-C, Zeleznik N, Economides S, Gschwind R, Abelshausen B, Savu D, Liutsko L, Charron S, Turcanu C, Geysmans R. 2020. Engaging health professionals and patients in the medical field: Role of radiological protection culture and informed consent practices. Radioprotection 55(HS2). https://doi.org/10.1051/radiopro/2020039.

Siar SV. 2005. E-governance at the local government level in the Philippines: An assessment of city government websites. Philipp. J. Dev. 32: 135-168.

Smallman M. 2016. Public Understanding of Science in turbulent times III: Deficit to dialogue, champions to critics. Public Understanding of Science 25(2): 186-197.

Stirling A. 2008. "Opening up" and "closing down" power, participation, and pluralism in the social appraisal of technology. Sci. Technol. Hum. Values 33(2): 262-294.

Suri H. 2011. Purposeful sampling in qualitative research synthesis. Qual. Res. 11(2): 63-75.

Turcanu C, Pölzl-Viol C, Fallon C, Perko T, Cantone M-C, Zeleznik N. 2019a. Report on venues, challenges, opportunities and recommendations for stakeholder engagement in relation to indoor radon exposure. CONCERT Deliverable D9.91.

Turcanu C, Abelshausen B, Geysmans R, Van Oudheusden M, Meskens G, Schieber C, Schneider T, Zeleznik N, Pölzl-Viol C. 2019b. Final report of the ENGAGE project. CONCERT Deliverable D9.94.

Turcanu C, Schieber C, Schneider T, Fallon C, Geysmans R, Perko T, Cantone M-C, Economides S, Barazza F, Charron S, Gschwind R, Lafage S, Zeleznik N, Pölzl-Viol C. 2020. Stakeholder engagement in the management of indoor radon exposures. Radioprotection 55(HS2).

Turnhout E, Van Bommel S, Aarts MNC. 2010. How participation creates citizens: Participatory governance as performative practice. Ecol. Soc. 15(4): 26-41.

van den Hoonard W. 1997. Working with sensitizing concepts. Analytical field research. London: Sage.

Wynne B. 2007. Public participation in science and technology: Performing and obscuring a political-conceptual category mistake. East Asian Sci. Technol. Soc. Int. J. 1(1): 99-110.

Zeleznik N, Turcanu C, Abelshausen B, Perko T, Meskens G, Geysmans R, Van Oudheusden M, Pölzl-Viol C, Cantone M-C, Veronese I, Liutsko L. 2019a. Rationales and frameworks for stakeholder engagement in radiation protection. CONCERT Deliverable D9.85.

Zeleznik N, Turcanu C, Abelshausen B, Perko T, Meskens G, Geysmans R, Van Oudheusden M, Pölzl-Viol C, Cantone M-C, Veronese I, Liutsko L, Zorko B. 2019b. Stakeholder engagement in radiation protection: Transversal issues and specifics of different exposure contexts. CONCERT Deliverable 9.86.

Zeleznik N, Pölzl-Viol C, Geysmans R, Turcanu C, Abelshausen B, Schieber C, Duranova T, Zorko B, Liutsko L. 2019c. Venues, challenges, opportunities and recommendations for stakeholder engagement in emergency \& recovery preparedness and response. CONCERT Deliverable D9.90.

Cite this article as: Turcanu C, Van Oudheusden M, Abelshausen B, Schieber C, Schneider T, Zeleznik N, Geysmans R, Duranova T, Perko T, Pölzl-Viol C. 2020. Stakeholder engagement in radiological protection: Developing theory, practice and guidelines. Radioprotection 55 (HS2): S211-S218 